\title{
El factor uterino en el aborto
}

\author{
Dr. Guillermo López-Escobar. FACS-FICS. \\ Dr. Rafael Peralta
}

Como quiera que los influjos endocrinos previamente analizados intervienen en la preparación progravídica del endometrio con su rítmica sucesión de fase proliferativa y secretora, y del miometrio; las alteraciones anatómicas, histológicas y fisiológicas del albergue del huevo, congénitas o adquiridas, tienen que influír en la producción del aborto, ya sea por causa mecánica, o especialmente, por fenómenos funcionales, o porque actúen sobre él otros elementos ovulares o extrauterinos.

Son estas alteraciones uterinas las que nos proponemos estudiar enseguida y con tal fin hemos resumido esquemáticamente en el siguiente cuadro las más sobresalientes, para luego desarrollar brevemente cada una de éllas:

Endometrio:

\section{CUADRO No 1}

a) - Falla de acción luteínica. Falla de Glucógeno. Falla del Edema Corial.

Para que la función endometrial sea normal y cumpla con el objetivo de prepararse para anidar el producto de la concepción, conservarlo y favorecer su evolución futura, por medio de secreciones glandulares y líquidos nutritivos extracelulares, han de operar recíprocamente la acción hormonal y la respuesta que presente la mucosa uterina.

* Trabajo presentado al IV Congreso colombiano de Obstetricia y Ginecología. - Barranquilla, 1959. 


\section{CUADRO No 1 \\ FACTOR UTERINO}

1) Endometrio

Falla de acción Luteínica

Falia de Glucógene

Falla de Edema Corial

Fibrosis - Colagenosis

Infecciones Previas

Pólipos Endometriales

Hemorragia Decidual

2) Anomalías Congénitas

$\begin{array}{ll}\text { Uterus Didelphys Bicollis } & \text { (vagina septada) } \\ \text { Uterus Duplex Bicollis } & \text { (vagina simple) } \\ \text { Uterus Bicornis Unicollis } & \text { (vagina simple) } \\ \text { Uterus Septus } & \text { (completo) } \\ \text { Uterus Subseptus } & \text { (parcial) } \\ \text { Uterus Unicornis } & \\ \text { Uterus Arcuatus } & \text { (fondo cóncavo) } \\ \text { (Jarcho) (7) }\end{array}$

3) Miomas y Adenomiosis

4) Malposicrones Uterinas - Hysterasthenia Gravis

Retroflexiones fijas

Hiperanteflexiones

Hipercontractibilidad

5) Hipoplas?as??

6) Incontinencia del orificio cervical interno

\section{Adquiridas}

Congénitas

\section{7) Sinequias Endouterinas Traumáticas}

No queremos insistir en la falla de acción luteínica como causa de aborto, pues de todos es bien conocido que "un endometrio que no ha adquirido las características progestacionales, ya sea 
por falta de progesterona misma, o de primación previa estrogénica, o bien porque es un endometrio que no responde al estímulo hormonal por falta de desarrollo o por defectos inherentes, es un endometrio que no va a permitir una buena nidación. Sin embargo, queremos mencionar dos mecanismos resultantes probablemente de una insuficiente acción luteínica, que se nos hacen interesantes :

Se acepta que el elemento indispensable para la función alimenticia endometrial es la glucosa. Ella llega al endometrio por vía sanguínea, se fosforiza transformándose en fosfato de glucosa y por polimerización pasa al estado de glucógeno bajo el cual se deposita. La fosfatasa alcalina coopera en la conversión anterior y las enzimas líticas transforman el glucógeno en glucosa. Se supone que este proceso de glucogénesis endometrial se encuentra comprometido en muchos casos de aborto, tal vez un $50 \%$, al comprobarse al $26^{\circ}$ día del ciclo disminución de glucógeno y de enzimas líticas, concomitantes con una fase progestacional del endometrio pobremente desarrollada; así como en el huevo lesiones atróficas del corion, céjulas de Langhans hipodesarrolladas, hemorragia y necrosis desiduales, desprendimientos placentarios o placenta circunvallata.

Por otra parte, varios autores Engle (1), Moricard (2), han mostrado alrededor del $20^{\circ}$ día del ciclo endometrial, la existencia de un edema del corion. fenómeno fisiológico de acción estrogeno-progesterónico, muy factiblemente en relación con la nidación del huevo y cuya falla puede ser causa de nidación defectuosa y por ende de aborto.

\section{b) - Fibrosis Endometrial.}

En 1956 Masters de St. Louis y colaboradores (3), presentaron un grupo de 29 casos de abortadoras de repetición, primarias o secundarias. En 17 de éllas la Biopsia Endometrial tomada posteriormente durante el estudio por el Servicio de Infertilidad, mostró el cuadro que ellos denominaron de Fibrosis Endometrial. En los casos avanzados el estroma endometrial se hace fibroso en exceso comprimiendo las glándulas que por lo general son escasas y con poca actividad secretora y el corte histológico es notoriamente avascular. En los casos moderados solo hay placas de tejido fibroso esparcidas. Los autores creen que esta fibrosis se origina en una infección endometrial post-parto o post- 
aborto y se expresa clínicaniente por disminución del flujo menstrual en tiempo y en cantidad y cuando la paciente queda embarazada por abortos de repetición. Sugieren como tratamiento raspado endometrial severo incluyendo buena porción de la basallis y bajo cubierta antibiótica para evitar nueva repetición de la infección.

De los 17 casos tratados en esta forma, en 10 cedió la fibrosis; uno fué tratado con Cortisona tópica sin éxito y en todos se aplicó Caproato de Hidroxiprogesterona a altas dosis (125 a 250 mgms. diarios i.m.) cuando se sospechó el nuevo embarazo. 9 de las 10 pacientes en las que la fibrosis había cedido, lograron por lo menos un embarazo viable, en cambio de las siete restantes, solo dos lo lograron.

Esta idea de la fibrosis endometrial, así como la de la colagenosis, es muy interesante y debe ser tenida en cuenta por aportar otro factor materno definido y abocar el problema de los huevos anormales desde el punto de vista etiológico materno sin tomar la actitud derrotista de que todo aborto es el resultado de un huevo genéticamente anormal. Sin embargo, hasta el presente es solo una inquietud. Como bien lo dice Mc. Clure en la discusión del trabajo de Masters, uno esperaría mejor una esterilidad verdadera que un aborto, en un endometrio con la severidad de la fibrosis descrita. Por otra parte el éxito de los casos de Masters podría ser atribuíble a las altas dosis de Progesterona dadas en inyección diaria con su posible doble acción comentada en la sección de tratamiento, de acción progestacional y acción psicoterapéutica. Además existen al parecer casos de fibrosis endometrial ligera que no han presentado abortos.

Entre nosotros mediante los estudios histopatológicos realizados por el Profesor H. Latorre, se han estudiado 23 casos de la clientela particular del Profesor Peralta y 53 casos de clientela hospitalaria, que presentaremos escuetamente como inquietud etiológica, sin considerar resultados. Así: De 23 casos particulares se estudiaron: En aborto inmediato 13 y fuera del embarazo 10. De los 13 primeros hubo fibrosis en 8, cuatro de los cuales tenían antecedentes de aborto. De las 10 observaciones fuera del embarazo, hubo fibrosis en 8 ; en 5 existía el antecedente de aborto, 3 de las cuales eran abortadoras de repetición. Los 53 casos de clientela hospitalaria, constituirán motivo de un informe futuro del Dr. Latorre. Hasta ahora no es posible sacar de ellos 
ninguna conclusión terapéutica. Lo único en claro, ha sido la existencia de la entidad y su relación frecuente con el aborto.

c) - Infecciones Previas.

Las infecciones endometriales demasiado profundas son causa de esterilidad pura, más que de aborto. Sin embargo, las infecciones pasajeras pueden producir en el endometrio trastornos que no le permitan ni un buen desarrollo, ni una buena nidación. Así, el hallazgo de un $11 \%$ de endometritis (Javert) (4), es considerado por De Vignes como el factor causante del aborto y no el resultado del mismo. Así también, en los comentarios presentados por Masters en la discusión de los casos de fibrosis endometrial a que nos hemos referido previamente, él hace hincapié en que: "probablemente el hecho más importante es el cubrir con antibióticos a la paciente durante todo el tiempo que esté amenazando abortar o cuando esté ya realmente expulsando el producto de la concepción". Las infecciones juegan también un papel relativo en la produccićn de sinequias intrauterinas que comentaremos al final de este capítulo y que ocasionalmente son causa de aborto.

d) - Polipos Endometriales.

Javert (4) encontró un $12 \%$ de poliposis endometrial en el grupo de raspados practicados por aborto, en contraste con un $2 \%$ en el grupo de contro!. Dos de los pólipos contenían la implantación de un temprano huevo. Algunos otros autores han publicado hallazgos similares y se comprende como la nidación de un huevo en un pólipo que es un elemento pediculado, tiene que sufrir deficiencias de nutrición que lo lleven al aborto en repetidas ocasiones.

Overstreet (5), en un estudio de 300 casos, anota que las mujeres con poliposis endometrial, estadísticamente parecen tener una mayor fertilidad, pero sufren de aborto más frecuentemente que el promedio de la población.

e) - Hemorragia Decidual.

El trofoblasto al invadir el endometrio produce hemorragias pequeñas que muchas veces al llegar la invasión de los vasos de- 
ciduales, se hacen aparentes al exterior, tanto que han merecido la categoría de signo: El Signo de Implantación al cual recurrimos muchas veces los clínicos para explicar la sangre que aparece alrededor de la posible fecha menstrual en la iniciación de un embarazo. Esta hemorragia decidual fisiológica es controlada por los factores de coagulación usuales, pero cuando estos mecanismos de coagulación son defectuosos: Deficiencias de caicio, de riboflavonoides, de fibrinógeno, de vitamina $\mathrm{K}$, hipoplaquetemias, etc., la hemorragia puede llegar a convertirse en una verdadera hemorragia patológica que al igual que la hemorragia retroplacentaria, más tarde, puede causar el aborto. Por otra parte, Javert (4), ha insistido sobre la posibilidad de que en mujeres por encima de los 40 años, pueden existir hemorragias deciduales por los mismos defectos vitamínicos u hormonales y ello explicaría la frecuencia de abortos en pacientes añosas.

Se comprende qué tan difícil es en la práctica comprobar esta hemorragia decidual, ya que al final de todo aborto, cualquiera que sea su causa llega a esta hemorragia decidual. Se necesitaría un estudio similar al sorprendente trabajo de Rutherford quien tomó biopsias deciduales de cien pacientes consecutivas en el comienzo de amenaza de aborto. Estudio que pocos investigadores quisieran emprender y que aun más, pocas pacientes estarían dispuestas a soportar.

En la relación con el aspecto histoquímico de la decidua, Galvis M. (6), encontró que sólo 4 de 21 abortadoras habituales poseían una distribución normal de las reacciones histoquímicas estudiadas. El resto mostraban anomalías consistentes en: Disminución o negatividad de los polisacáridos principalmente glucógeno, (15 casos), disminución o negatividad del ácido ribonucleico ( 9 casos) y reacciones anormalmente positivas de fosfatasa alcalina (10 casos).

\section{ANOMALIAS CONGENITAS UTERINAS}

La Clasıficación de Jarcho (7), citado a continuación, es de las más simples, es clínicamente adecuada y cubre la mayoría de estas anomalías, dejando de lado tan solo las más desusuales como el útero bicorne con cuerno rudimentario, ectópico, u ocluído. 


\section{Clasificación de Jarcho}

$\begin{array}{ll}\text { Uterus Didelphys Bicollis } & \text { (vagina aceptada) } \\ \text { Uterus Duplex Bicollis } & \text { (vagina simple) } \\ \text { Uterus Bicornis Unicollis } & \text { (vagina simple) } \\ \text { Uterus Septus } & \text { (completo) } \\ \text { Uterus Subseptus } & \text { (parcial) } \\ \text { Uterus Unicornis } & \\ \text { Uterus Arcuatus } & \text { (fondo cóncavo) }\end{array}$

La mayoría de los autores están de acuerdo en que las anomalías congénitas uterinas son una causa de parto prematuro y de aborto cuya incidencia varía en ellas de un 27 a un $53 \%$. Hay solo algunos pocos como Baker (8), que no confirman esta apreciación. En lo que no hay acuerdo es en cual tipo de malformación es la mayor productora de abortos. Nuestra impresión a grosso, es de que las anomalías más completas tipo 1 y 2 por el hecho de tener dos caviciades aisladas ocasionan menos frecuentemente abortos y que en muchos casos la inserción ovular se efectúa en el cuerpo más desarrollado pasando desapercibida la anomalía. Uzeda Moreno (9), ha publicado un caso que tuvo 9 gestaciones a término o sin ningún aborto. En cambio aquellos casos en donde existe una sola cavidad bicornada, septada o arcuada, la división puede constituír una espina irritativa que aumente la motilidad uterina. No debemos olvidar tampoco, que la anomalía puede incidir sobre el estado endometrial de por sí o porque la nidación se haga sobre un septum que no permite una inserción correcta del trofoblasto.

Smith (10), concluye que la tendencia al aborto es mayor en aquellos tipos de anomalías que ocasionan una situación transversa o una pelvis.

Repetidas veces el médico práctico no piensa en estas anomalías cuando se halla en presencia de una abortadora. Por ello creemos necesario hacer érfasis en que el estudio posterior de una paciente a quien se le trata de investigar la causa de sus abortos no puede ser completo sin una Histerosalpingografía que en buen número de casos nos sorprenderá con la demostración de una anomalía congénita, y en otros nos dará la clave, al hallar otro factor uterino: Mioma, incontinencia cervical, sinequias, etc. 
Seguidamente queremos presentar en forma breve algunos casos ilustrativos que nos permitirán hacer algunos otros comentarios.

\section{A. S. de $\mathbb{B} .-$ H. C. № 2.349}

Paciente de 25 años, casada a los 22 años. Ha tenido 8 abortos espontáneos de 8 a 16 semanas aproximadamente. La Histerosalpingografía mostró UTERO BICORNIS UNICOLLIS (VAGINA SIMPLE) cuello ligeramente ancho e irregularidad en endocérvix. El resto del estudio de la pareja descubrió hipotiroidismo ligero del marido con testículo izquierdo atrófico y espermograma ligeramente bajo (90 millones). Han sido tratados previamente con hormonas, psiquiatría, etc., etc. Creemos que este es un caso en que un tratamiento quirúrgico plástico similar a la operación plástica recomendada por Strassmann, está indicado.

\section{o. Q. de $\mathbb{F}$. - H. C. $\mathrm{N}^{\circ} 1.364$}

Paciente de 25 años. Casada a los 21. Primer embarazo a término de pelvis con feto vivo, murió más tarde. Posteriormente dos abortos de 22 y 12 semanas. Histerografía. (Fig. No 1) mostró UTERO BICORNE UNICOLLIS con cavidad derecha más grande. Es interesante anotar que durante la Histerografía, se comprobó a la Fluoroscopia contracciones antiperistálticas de la cavidad derecha, netamente visibles. El resto del estudio fue negativo. Este es uno de los casos en que creemos que si la inserción placentaria se hace sobre la cavidad derecha, la paciente retenárá el embarazo como sucedió en el primero, y en cambio, elucubramos que cuando el huevo se inserta en la cavidad izquierda, lo aborta.

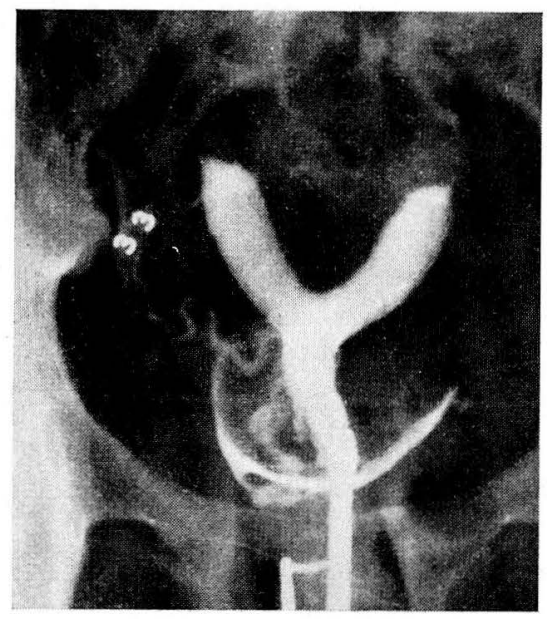

FIGURA Nọ 1 - Uterus bicornis unicollis. (Vagina simple). 
C. C. de M. - H. C. $\mathrm{N}^{0} 2.345$

Paciente de 23 años, casada a los 20. Ha tenido 4 abortos espontáneos entre 8 y 16 semanas aproximadamente. La Histerosalpingografía mostró UTERO BICORNIS UNICOLLIS CON CAVIDAD DERECHA MAS DESARROLLADA Y ANTEVERSO FLEXION (Fig. No 2). (En parte artificio esta última).

FIGURA No 2 - Uterus bicornis unicollis. (Vagina simple).

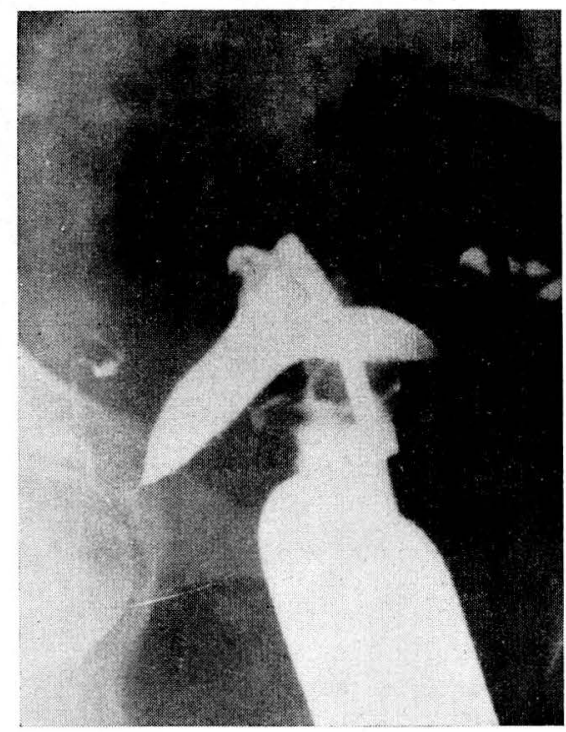

El estudio complementario mostró ligero hipotiroidismo de ambos, con exceso de peso del marido. Actualmente lleva un embarazo con fecha de confinamiento Enero 20 de 1960. Ha sido tratada con Triodotironina, riboflavonoides, estrógenos y progesterona. Creemos que este es uno de los casos a que nos hemos referido en el texto en el que el tratamiento mejoró las condiciones endometriales de nidación y permitió el desarrollo del embarazo hasta ei presente a pesar de la malformación del útero.

R. D. de T. - I. M. I. N. 8.144 (publicado por el Dr. Navas Angel en la Rev. Col. de Obst. y Ginec. V. 8 No 6 P. 357).

Paciente de 30 años. Su prinier embarazo termina en aborto a las 12 semanas. Posteriormente hace un embarazo en el que a las 32 semanas se le diagnostica UTERO DIDELPHYS BICOLLIS (VAGINA SEPTADA) con feto alojado en la cavidad derecha y miomas en el cuerpo izquierdo. Al término se practicó Cesárea Segmentaria pues el hemiútero izquierdo actuó como tumor previo. Posteriormente hace dos nuevos embarazos ambos de la cavidad izquierda miomatosa que terminan en cesárea con feto vivo pues el hemiútero derecho esta vez, actuó como tumor previo. Este caso recuerda lo que mencionábamos en el texto, acerca de que cuando existen dos cavidades aisladas, 


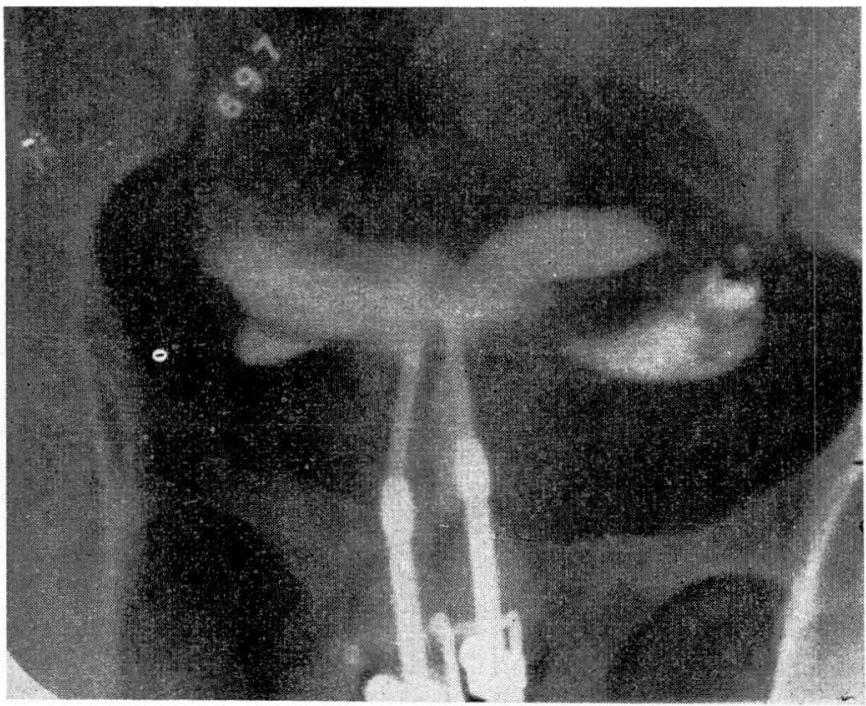

FIGURA No 3 - Uterus didelphys bicollis. (Vagina Septada).

suficientes, por lo general el embarazo progresa normalmente. Se necesita naturalmente, resecar el tabique vaginal para el parto.

Las figuras 1 a 4 muestran las imágenes radiográficas de 4 casos diferentes de anomalias uterinas congénitas.

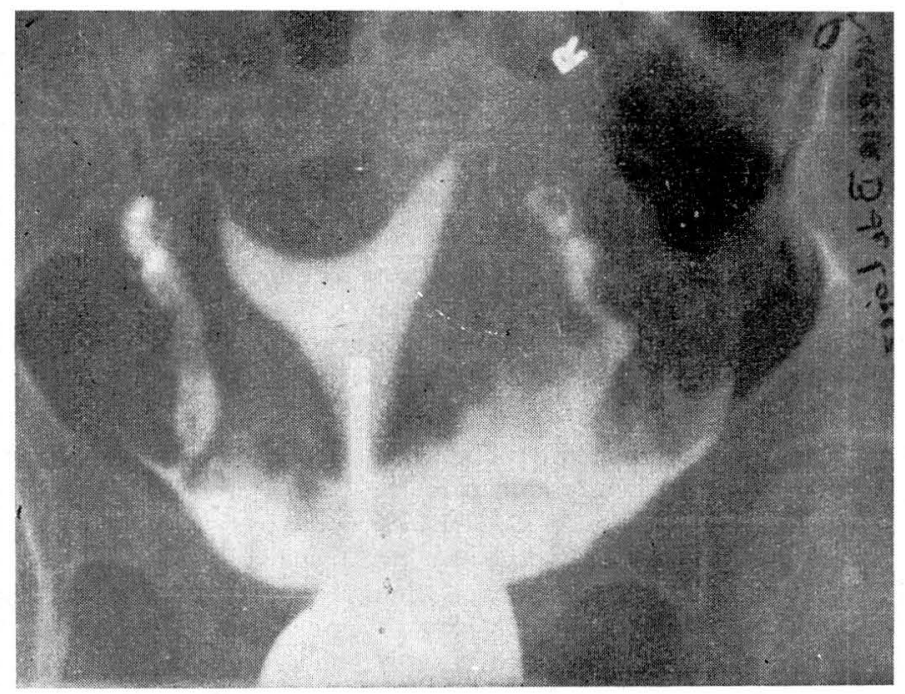

FIGURA No 4 - Uterus arcuatus. 


\section{MIOMAS Y ADENOMIOSIS}

A pesar de que se dice que los miomas uterinos producen abortos, su valor causal en la entidad que nos ocupa no es tan grande como clásicamente se ha afirmado. Frecuentemente se sorprende el obstetra al ver úteros con grandes miomatosis de todo género, llevar un embarazo a término (ver figura № 5 ). East-

FIGURA No 5 - Miomatosis. Histerosalpingografía.

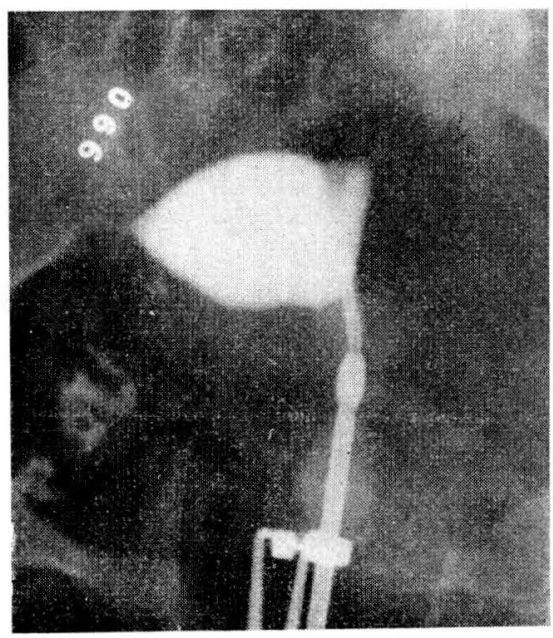

man (11), :tfirma que: "Los fibromiomas del útero usualmente no son causa de aborto y que probablemente es la situación submucosa del tumor la que es más dable de producir aborto". La única prueba que nos indica si un útero miomatoso va a abortar es la prueba clínica. Tal vez, en muchos casos no es el fibroma el causante del aborto, sino las alteraciones endometriales o de contractilidad concomitantes con él. Esto explicaría en parte los éxitos obtenidos en pacientes miomatosas que han abortado y que luego con tratamientos coadyuvantes sin la extirpación del mioma, han logrado llegar al término de una preñeż.

Así en el caso R. T. de B. H. C. № 1.738, paciente de 28 años que aborta a las 10 semanas de su primer embarazo y a la cuas se le encuentra un mioma de unos 3 ctms. de diámetro, se le insiste en que tenga un nuevo embarazo después de estudio complementario que revela solamente ligero hipotiroidismo del marido con exceso de peso. El nuevo embarazo con tratamiento coadyuvante, llega a término y obtiene una niña viva de $3.500 \mathrm{grms}$. 
Es claro que en una abortadora habitual la miomectomía está indicada. Así Javert (4) encontró que los miomas eran la lesión uterina más común en el aborto habitual con una frecuencia del $21 \%$, o sea el doble de la encontrada en pacientes con aborto espontáneo y triple a la de las pacientes en general. Pero él mismo, relata tres casos en los que en un parto a término, la mujer sangró excesivamente por un mioma submucoso, o lo expulsó en el temprano puerperio.

Muy ocasionalmente la placentación en un sitio de adenomiosis puecie ser causa de aborto.

\section{MALPOSICIONES UTERINAS HISTERASTHENIA GRAVIS - HIPOPLASIAS}

El concepto de la Retrodesviación Uterina, ha venido modificándose a través de los tiempos para adquirir sus verdaderas proporciones; de la época antigua en que ella era considerada como verdaderamente patológica. hemos llegado a la época actual en que creemos que para multitud de mujeres la Retroflexión Uterina es una posición normal. A nuestro modo de ver el útero es un órgano móvil y solo puede considerarse como posible causa de aborto a las Retroflexiones Fijas. Aun en éstas, las adherencias pueden ablandarse y alargarse influenciadas por el empuje hormonal del embarazo para permitir la salida y el crecimiento extrapélvico del útero embarazado. La mayoría de las veces la retrodesviación uterina va a evolucionar espontáneamente durante el embarazo hacia la curación. En el raro caso en que esto no sucede, se produce el aborto y/o la incarcelación o la saculación.

Es difícil aceptar la H:peranteflexión uterina como causa de aborto. No obstante ella podría incluírse dentro del grupo de la "Hysterasthenia Gravis", término acuñado por Javert y que él define como "Hipertonicidad e irritabilidad aumentada del útero embarazado". Numerosos autores han señalado la posibilidad de que el origen del aborto puede estar en una hipertonía uterina ocasionada por factores psicosomáticos y que en la misma forma en que un individuo reacciona con espasmos pilóricos, taquicardias, hiperventilación, etc., puede reaccionar con contracciones uterinas violentas.

De observación corriente son los abortos producidos con ocasión de choques emocionales o stress. Así mismo, algunas abor- 
tadoras habituales bien sea porque rechazan el embarazo consciente o inconscientemente, o bien por complejos provenientes de la infancia, los padres o la educación sexual recibida, responden ante el embarazo con una excesiva contratibilidad uterina y se pudiera decir que a base de ella logran hacerse abortar por mecanismos inconscientes psico-neuro-endocrinos.

Algunos de los llamados úteros infantiles o hipoplasias uterinas encajarían mejor dentro de este cuadro de Hysterasthenia gravis, al abortar por incapacidad de distenderse, otros se acompañan de incontinencia cervical. Nosotros creemos que la verdadera hipoplasia uterina es causa más bien de esterilidad primaria, que de aborto.

\section{INCONTINENCIA DEL ORIFICIO CERVICAL INTERNO}

Los trabajos de Danforth (12) y Steve, mostraron gráficamente cómo desde el final del primer trimestre del embarazo, a medida que la porción ístmica del útero se distiende y dilata, para adaptarse al huevo en crecimiento, el cuello es el que retiene al huevo por su constitución fibrosa y por el estrechamiento de su orificio interno que actúa como esfínter.

Palmer y Lacomme (13), fueron los primeros en llamar la atención sobre el papel de la incontinencia ístmico-cervical como factor causante de aborto y más tarde, Lash (14), MacDonald, Shirokdar y Bergman (15) y (16) y otros han puntualizado su diagnóstico y tratamiento. Desde que la entidad se reconoció, día a día, se describen más casos.

El orificio cervical interno, puede ser incompetente congénitamente, pero la mayoría de las veces su incontinencia es adquirida, consecuente a partos traumáticos o a procedimientos quirúrgicos como amputaciones cervicales altas o dilatación y raspados uterinos, o bien a dilataciones manuales en el momento del parto, tan usadas en nuestro medio, procedimiento proscrito en la obstetricia rnoderna y del que gráficamente se ha dicho que no debe denominarse "Dilatación manual", sino "Laceración manual". Las laceraciones resultantes pueden ser aparentes, pero para que elias hagan el cuello incontinente, es necesario que suban hasta el orificio interno. En otras ocasiones, cuellos aparentemente sanos son incompetentes por laceraciones internas no visibles al simple speculo. 
Varios elementos de juicio nos ayudan al diagnóstico de la incontinencia cervical: La Historia por lo general es típica, se trata de abortos espontáneos, poco dolorosos que se suceden al comienzo del segundo trimestre del embarazo si el cuello es totalmente incompetente o más tardíamente si el defecto es parcial. Danforth (loc. cit.) anota que la duración del embarazo es inversa a la extensión del defecto. Al examen clínico ocasionalmente pueden observarse las membranas fetales abombando a través del orificio cervical parcialmente dilatado y en la paciente no embarazada, el dedo o una bujía de Hegar $N^{0}$ 8, penetran sin resistencia a la iavidad uterina a través del canal cervical. La Histerografía hace aparente el defecto mostrando un canal ístmico cervical ancho y Palmer insiste en que cada vez que la anchura de éste es mayor de $8 \mathrm{~mm}$. el diagnóstico debe ser propuesto. Asplund, da como margen $6 \mathrm{~mm}$. Bergman y Svennerud creen que si bien la Histerografía es un buen método diagnóstico, las variaciones del ángulo uterino, de la presión con que se inyecta el medio de contraste y la fase del ciclo menstrual hacen su interpretación difícil y por eilo han ideado un método en el cual introducen dentro de la cavidad uterina, un catéter de Fowley $\mathrm{N}^{\text {o }}$ 16, cuyo balón llena con $1 \mathrm{~cm}$. de solución salina y con un mandril de metal encorbado al cual enganchan un medidor de presión de resorte. El cuello incompetente deja salir el balón con tracciones por debajo de $600 \mathrm{gms}$. El cuello continente, generalmente resiste tracciones por encima de 1.000 gramos. Rubowitz, ha ideado un método similar con un balón controlado bajo fluoroscopia. Palmer y Bergman, señalan la fase luteal como el momento más adecuado para practicar la Histerografía o los tests de potencia arriba citados, ya que es el momento en que el comportamiento muscular recuerda más a la gestación. Sin embargo, los trabajos de los autores suecos no confirman esta impresión y nosotros la hemos practicado en cualquier época del ciclo, más frecuentemente en la fase post-menstrual.

Las figuras 6 a 11 y los siguientes resúmenes de casos ilustran este sugestivo factor causal abortivo uterino:

o. G. de F. - H. C. $\mathrm{N}^{\circ}$ 2.372. (Ver Fig. $\mathrm{N}^{\circ}$ 6)

Paciente de 33 años. Casada a los 26 años. Primer embarazo termina en aborto de 12 semanas. Segundo embarazo, parto prematuro de 32 semanas con niña viva, después de haber permanecido acostada la mayor parte del embarazo. Posteriormente dos abortos espontáneos de 12 y 15 semanas. El exa- 
FIGURA No 6 - Cuello incontinente.

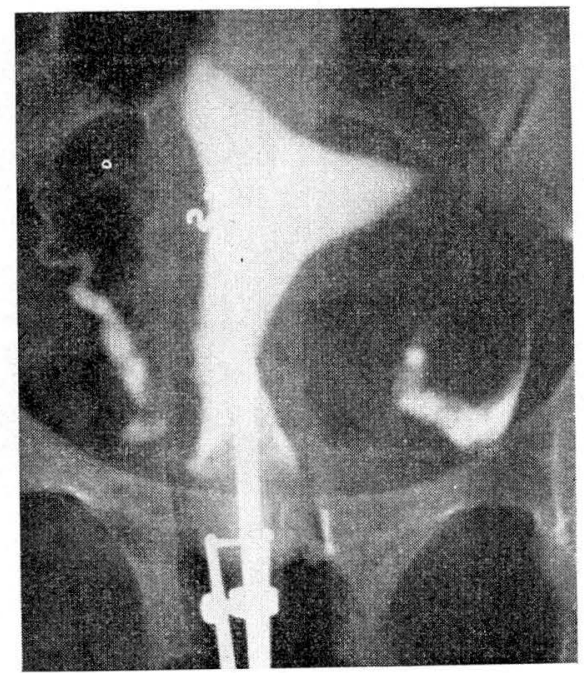

men muestra laceración cervical que llega hasta el fondo de saco vaginal derecho. La histerografía confirma el cuello incontinente.

N. C. de E. - H. C. No 1.739 . (Ver Fig. No 7)

Paciente de 26 años. Histerosalpingografía muestra Cuello Incontinente.

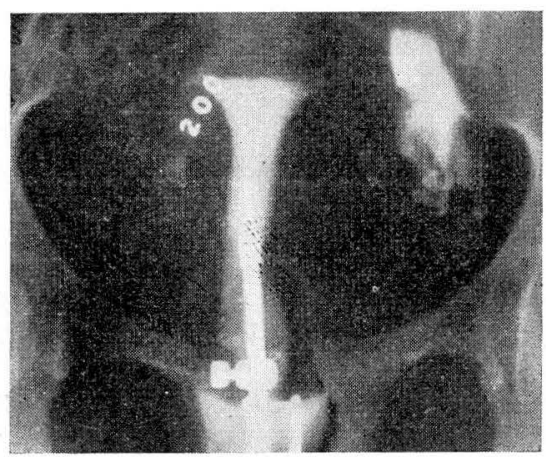

FIGURA $\mathrm{N}^{0} 7$ - Cuello incontinente.

M. C. T. da A. - H. C. No 2.537. (Ver Figs. 8 y 9)

Paciente de 22 años. Casada a los 20 años. Posteriormente dos abortos de aproximadamente 20 semanas. Al examen cuello uterino con mínima erosión. La Histerosalpingografía muestra Cuello Incontinente. 

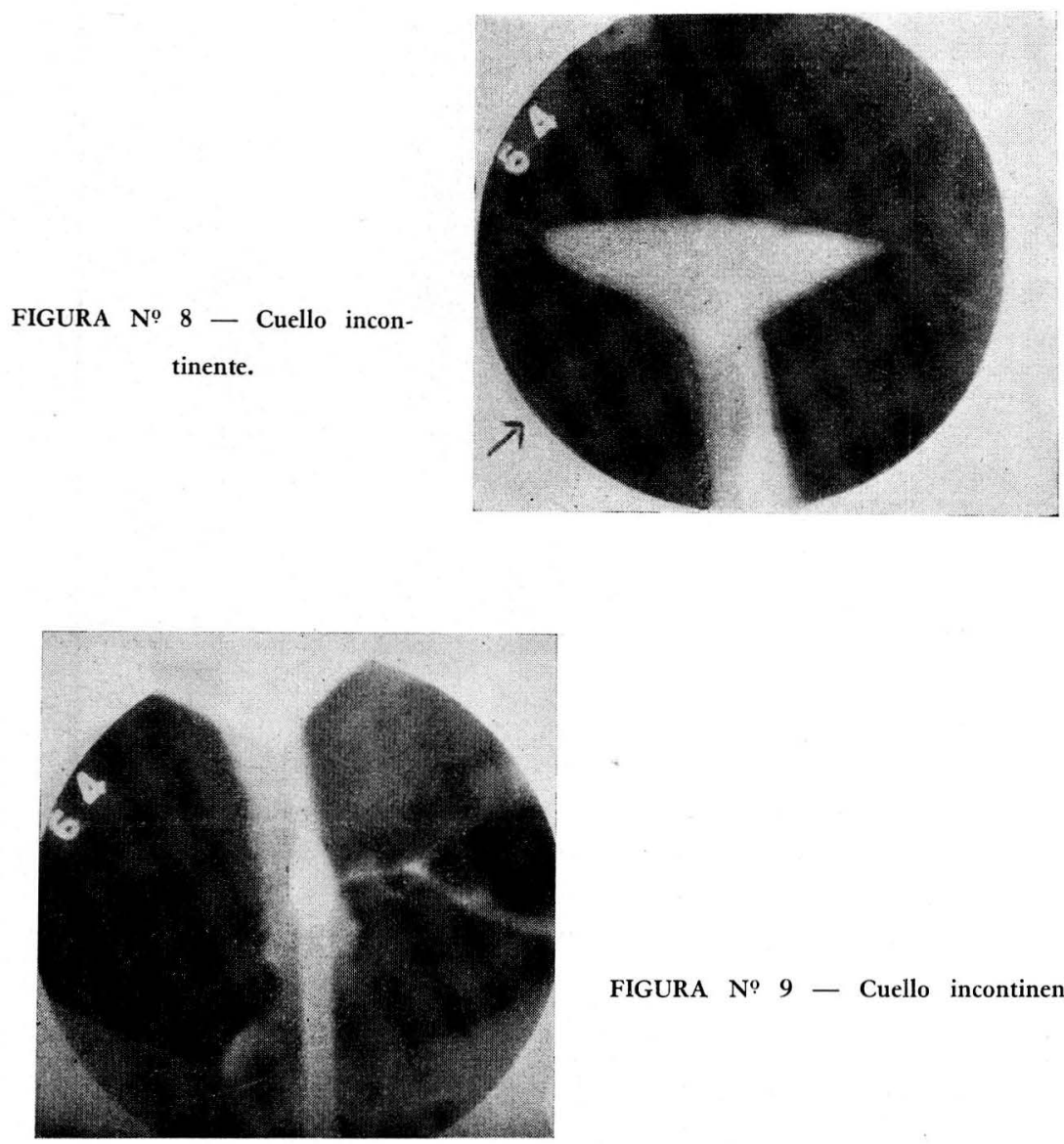

FIGURA No 9 - Cuello incontinente.

C. P. de R. P. - H. C. No 1.061

Edad, 39 años. Casada a los 27 años. Cinco embarazos con partos a término, partos difícıles con niños de 7 a 11 libras. Un aborto temprano. Posteriormente parto prematuro de 26 semanas. Al examen, grandes laceraciones cervicales en especial hacia la comisura derecha, pero que en ambos lados llegan hasta el fondo de saco vaginal. En octubre 24/56, se practica traquelorrafia de Emmett que cicatriza bastante bien. En 1958, parto a término con feto masculino de 3.900 gms. La paciente no volvió a su control post-natal, de tal modo que en ese tiempo no se supo qué suerte corrió el cuello en ese parto. Más tarde en 1959, nuevo embarazo con aborto, aproximadamente a las 15 semanas. En esta paciente se nota el efecto que tuvo la traquelorrafia para retener un embarazo en cuyo parto se rompió la plastia practicada en el cuello dejando de nuevo la laceración que le produjo otra vez un aborto. 


\section{A. de S. - H. C. No 2.106 (Ver Fig. No 10 ).}

Edad, 33 ańos. Casada a los 25 años. Tres embarazos con parto a término, normal. Luego un aborto de 8 semanas. Luego otro embarazo con parto a término y últimamente dos abortos de 6 a 8 semanas. Presentamos la imagen de la Histerosalpingografía por comparación, pues es un cuello que a pesar de la multiparidad y de los abortos, es perfectamente continente y normal. La pareja no ha querido continuar el estudio complementario.

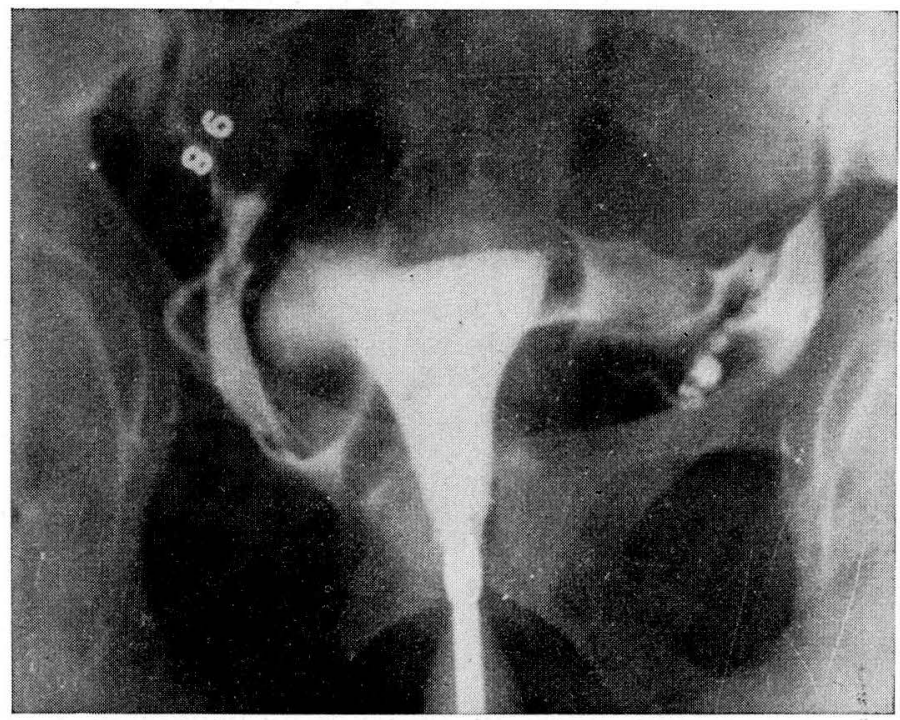

FIGURA No 10 - Cuello normal. A pesar de multiparidad y de abortos.

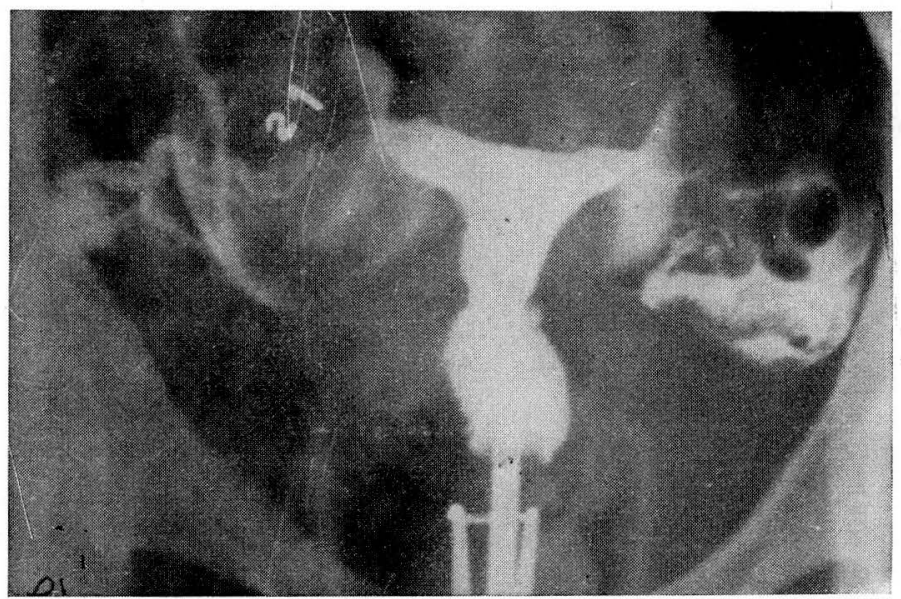

FIGURA № 11 - Cuello irregular por mioma cervical. 
L. C. de M. - H. C. № $2.51 \mathrm{i}$ (Ver Fig. 11)

31 años. Casada a los 26 años Estéril. Presentamos la Histerosalpingografía por comparación, pues a pesar de que aparece como un cuello incontinente a primera vista, se ve que "es un cuello irregular y que la incontinencia es producida por una irregularidad cervical comprobada al examen clínico, probablemente un mioma.

\section{SINEQUIAS ENDOUTERINAS TRAUMATICAS}

Terminamos este capítulo sobre el factor uterino, llamando la atención sobre la entidad descrita por Asherman de Israel en 1948 (17) y subrayada por Netter y colaboradores (18): Las Sinequias Uterinas Traumáticas.

No muy raramente un raspado uterino demasiado fuerte o repetido, post-aborto y especialmente post-parto o el simple taponamiento uterino puede conducir a la producción de adherencias intrauterinas que en ocasional caso llevan hasta la oclusión casi total de la cavidad uterina. Ellas son causa frecuente de hipomenorreas y llegan a amenorrea que cede muy poco a los tratamientos hormonales. El albergue uterino distorsionado por estas adherencias es un nido muy pobre para el huevo y si la nidación tiene lugar fácilmente se sucede el aborto o el parto prematuro. El diagnóstico puede sospecharse por el resalto o la dificultad que encuentra el histerómetro a su paso y se confirma por la Histerografía, cuyas placas muestran defectos de llenamiento que adoptan los aspectos más variados y que muchas veces son interpretados como pólipos, crecimientos uterinos o burbujas de aire.

Es curioso que dentro de los trabajos mencionados en este capítulo, en uno se haga énfasis y se proponga como tratamiento raspado uterino intenso si es posible llevándose la basal (Véase fibrosis uterina), y por otri parte se hable de los peligros y resultados traumáticos de tales raspados. iIncongruencias de la Medicina, arte y ciencia a la vez!

El tratamiento de las sinequias intrauterinas es quirúrgico. Tanto Ashermann como Netter, aconsejan la vía abdominal. Pero al tratar estas pacientes, no debemos olvidar que. como lo describe Ashermann, estamos tratando una causa adicional de aborto y no la sausa primaria, ya que son mujeres que han tenido abortos previos a las sinequias, y por esto es necesario agotar en ellas todos los métodos de investigación y de tratamiento de valor causal en el aborto. 


\section{BIBLIOGRAFIA}

1) E. T. ENGLE. Human Infertility. C. L. Buxton y A. L. Southman Hoeber - Harper Ed. 1958, N. Y.

2) R. MORICARD et al. Unidia. V. II No 9. Sep.-Oct. 1954. p. 781.

3) W. MASTERS et al. Am. J. Obst. y Ginec. 73 No 5 Mayo 1957.

4) C. T. JAVERT Spontaneous and Habitual Abortion. McGraw-Hill Ed. 1957. N. Y.

5) OVERSTREET J. The Relationship of Endometrial Polyposis to Fertility and Abortion. Tercer Congreso Mundial de Fertilidad y Esterilidad. Excerpta Médica. Jun. 7-13/59.

6) M. GALVIS. Investigaciones Histoquímicas de la Decidua del Aborto Habitual. Tercer Congreso Mundial de Fertilidad y Esterilidad. Excerpta Médica. Jun. 7-13/59.

7) N. W. PHILPOTT et. al. Congenital Uterine Anomalies and Associated Complications of Pregnancy. Am. J. Obst. \& Gynec. 68 No 1 Jul./54. p. 285.

)8 BAKER Am. J. Obst. \& Gynec. 66-580 1953.

9) UZEDA MORENO. (Citado por J. Adeodato) Filho Gravidez em Utero Duplo. Obst. Gynec. Lat. Amer. XIII Nọ 6 Jun. 1955.

10) SMITH, Am. J. Obst. \& Gynec. XXII No 5 Nov./51 p. 714.

11) EASTMAN. William's Obstetrics 11th Ed. Appleton-Century-Crofts Inc. Ed. N. Y. 1956.

12) DANFORTH y STIEVE. The Fibrous Nature of the Human Cervix and its Relation to the Isthmic Segment in Gravid and non Gravid Uteri. Am. J. Obst. \& Gynec. 53-541 1947.

13) PALMER y LACOMME. Le de la Beance de L'Isthme Uterin dans L'Avortement Habituel. Rev. Franc. de Gynec. No 5 Sep.-Oct. 1950.

14) A. F. LASH. Habitual Abortion the Management of Incompetent Internal os of the Cervix. Int. J. of Fertility V. II No 4 Oct.-Dec./57. p. 321 .

15) P. BERGMAN y S. SVENNERUND. Traction test for demostracting incompetence of the Internal os of the Cervix. Int. J. of Fertility. V. II No 2 Apr. Jun. 1957. p. 163.

16) P. BERGMAN et. al. Incompetence of the internal os of the Cervix and habitual abortions. Int. J. of Fertility V. II No 3 Jul-Sept./57. p. 217. 
17) ASHERMANN J. Traumatic Intrauterine Adhesions. J. Obst. \& Gynec. Brit. Emp. 57 No 6-892. 1950. p. 892-896.

18) NETTER et. al. Traumatic Uterine Synaechiae. Am. J. Obst. \& Gynec. 71 No 2 Feb./56. p. 368-375.

19) R. B. WILSON. Habitual Abortion. Am. J. Obst. \& Gynec. 69 No 3 Marzo 1955, p. 614.

20) F. H. FALLS. Pregnancy in the Bicornuate Uterus. Am. J. Obst. \& Gynec. V. 72 No 6 Dec./56. p. 1243.

21) H. NAVAS. Sobre un caso de Duplicidad Genital Femenina. Rev. Col. de Obst. y Ginec. V. VIII. No 6 Nov.-Dic./57. p. 357. 